\title{
Negative impacts of an unwelcoming physics environment on undergraduate women
}

\author{
Lisabeth M. Santana and Chandralekha Singh \\ Department of Physics and Astronomy, University of Pittsburgh, Pittsburgh, PA, USA 15260
}

This research focuses on the experiences of three undergraduate white women who are physics and astronomy majors. Specifically we conducted semi-structured, empathetic interviews which reveal how uncomfortable physics environments inside and outside of the classroom exclude undergraduate women. The women give accounts of the behaviors of their male peers and instructors that influenced the physics culture. We use standpoint theory to focus on the experiences of undergraduate women to provide a holistic perspective of physics as well as identify key issues that these women faced in their undergraduate physics program and potential strategies to implement in the future to support undergraduate women in physics and astronomy. Some of their suggestions include providing mentoring for women, holding members of the department accountable, providing feedback for instructors, and training sessions. 


\section{INTRODUCTION AND FRAMEWORK}

The underrepersentation of women in physics has been a focus of researchers for decades. Despite this focus, the number of physics bachelors' degrees granted to women has remained stagnant at approximately $20 \%[1,2]$, indicating that barriers for women still exist in the field. Many barriers for women and other underrepresented students in undergraduate Science Technology Engineering and Mathematics (STEM) disciplines have previously been documented [3-5]. Research also shows that women in many STEM disciplines have lower self-efficacy than men [6, 7].

Physics has the worst stereotypes among the natural sciences pertaining to who belongs in it and can excel in it [8]. The history of physics is narrated to students through the stories of brilliant men so that women continue to lack role models. Prior research shows that compared to men, women have lower perceived recognition as a "physics person" from peers and instructors [9-13], which can influence female students' decisions to leave the field [14]. In particular, if women believe that their instructors or peers do not see them as being capable of excelling in physics, it impacts their own beliefs about whether they can excel in physics [15]. Prior studies have also found that sense of belonging and self-efficacy in physics are closely intertwined [16]. Because improving self-efficacy is a multifaceted process [17], creating an equitable and inclusive learning environment that increases underrepresented students' sense of belonging may help increase their self-efficacy and improve their retention [18-22]. Thus, physics instructors and peers play a critical role in a woman's sense of belonging in the physics classroom and, more generally, as a physics major. Since men make up the majority of physics majors and physics professors in a department, they play a large role in establishing the physics culture whether that be inside or outside the classroom. Prior research supports the idea that the physics culture is geared towards a masculine culture, one that perpetuates stereotypes such as 'only men can understand physics' [23-26]. This masculine culture disadvantages women as they become isolated from lack of role models and a community that supports them [27, 28].

It is crucial to investigate women's experiences in physics learning environments in order to improve the physics culture. Quantitative data are useful for understanding the scope of the inequities, but qualitative data allow researchers to uncover the mechanisms via which inequities are perpetuated. It is through student interviews that we uncover a contextual understanding of how women experience and navigate the physics culture. Previous studies that utilize student interviews revealed that women in physics and astronomy experience hostile environments within physics departments $[29,30]$. In this study, we interview three undergraduate women who are physics majors. Based on their accounts, we investigate the physics culture, e.g., who the key players are that influence and propagate the culture and how it affects undergraduate women majors.

Our theoretical framework is based upon standpoint theory, which is a feminist critical theory that describes the relation- ship between the production of knowledge and acts of power [31]. It is related to other feminist and racial critical theories in that it centers around the standpoint or voices of the underrepresented groups that do not have the same privilege as the dominant group in order to gain a clearer understanding of their struggles. By using standpoint theory as our framework, we can highlight the voices of undergraduate women in physics and directly receive their input about how to improve the culture in a way that supports them. Standpoint theory is our theoretical framework specifically due to the fact that women in physics are underrepresented and their perspectives can provide more useful insight towards improving the physics culture and undergraduate student experiences $[32,33]$. This framework will be used to guide our analysis (e.g., the formation of codes and analytic themes). In this paper, we focus on how male peers and instructors contribute to a negative physics culture inside and outside the classroom, which negatively affects undergraduate women in physics. We also focus on the suggestions provided by these undergraduate women on how to improve their experiences in physics.

\section{METHODOLOGY}

We conducted semi-structured, empathetic interviews with 16 undergraduate women physics and astronomy majors at a large predominately white, research university. In this paper we analyzed three semi-structured, empathetic interviews that were each an hour long in duration. The interviews were followed by protocols established by the researchers prior to conducting the interviews [34]. Each student received a $\$ 25$ gift card for participating in the interview. We call these interviews empathetic interviews because the goal of the interviews is to understand the experiences of women in physics and astronomy in order to improve equity and inclusion, and the interviews focused explicitly on the physics culture. Importantly, with regard to the positionality, the interviewer was a woman of color, whose identities may have encouraged the female students to be more open in sharing their experiences.

We coded the interviews using hybrid coding methods [35]. One of the authors coded the interviews and both authors agreed on the codes developed based on the student interviews. Initially, deductive coding was used based on the interview protocols, but after reading through the interviews, we incorporated inductive coding to encompass different aspects of the women's experiences $[35,36]$. The codes themselves are inspired by the theoretical framework, standpoint theory $[32,33]$, in which we center the experiences of undergraduate women in physics in order to understand how to support them and improve the physics culture. The analytic themes (AT) that we used in this paper are:

AT1. Uncomfortable environments created by male peers

AT2. Uncomfortable environments created by male instructors

AT3. Suggestions for improving women's experiences

These themes lay the foundation for describing the experiences of these undergraduate women in the context of an 
alienating physics culture inside and outside of the classroom. In this paper, we recount interviews from Mary, a sophomore astronomy major, Samantha, a senior physics and astronomy major, and Evelyn, a senior physics and astronomy major, all of which are cis, white women.

\section{RESULTS AND DISCUSSION}

\section{A. Uncomfortable environments created by male peers}

All three women give various accounts inside and outside the classroom in which their male peers' comments alienate them and cause them to feel inferior. For example, Mary recalls studying with her male peers outside of class. During their study session, she felt that they were ignoring her inputs, not acknowledging them, and that they were not "really interested in what I had to say, or just like, assume their [idea] was gonna be better than mine." Her experiences suggest that male students' biases towards their female peers may interfere with their participation in group discussions. She also describes that as a woman, she feels that she has to prove herself to the men in her cohort, "I feel like I have to prove myself to the boys in ways that they don't have to prove themselves to each other and I feel like I don't necessarily immediately pass the test." Her experience corresponds to physics being a 'boys' club' in which male students push women out of learning spaces. Mary also suspects that her male peers do not see her as a physicist because of her traditionally feminine presentation. She says, "I'm like pretty girly,... I like to wear dresses, like do my hair do my makeup and stuff....and I think those things combined kind of,... like right off the bat, you wouldn't immediately assume that I'm good like at doing physics." In her opinion, her appearance does not match that of a traditional physicist and therefore she cannot identify as one. Thus, the masculine culture of physics in which female students feel like they have to "prove themselves" as worthy of studying physics, combined with ideas of who can do physics pushes away students like Mary.

Not only are these undergraduate women excluded from study groups which are composed of their male peers, they also are pushed away from common spaces, such as the physics lounge, a space where undergraduate physics and astronomy students can study and socialize. Another student, Samantha, explains that the student lounge is intimidating for her female peers because it is, "men's home base for like doing work and so they know like, 'if I go there, this person is going to be there and I have to like interact with them." She implies that this study space attracts students who use the space to socialize and could potentially perpetuate a negative space for women. Evelyn adds that whenever she went to the student lounge to study, she encountered students who would badger her with questions. She says "he always like, wants to talk about,... what class you're in and he'll be like, 'Oh, that class is very easy.' or like, 'Oh, this subject's very easy, I'm taking the grad level of that class.' and like, 'That's easy.' or 'I took that class and like, I read all these extra textbooks,' and like, completely unwarranted too. It's like, you can't really escape these comments." Here we see how un- dergraduate women avoid commons spaces due to male peers dominating the space both physically and with an 'I' $m$ better than you' attitude.

Samantha explains other ways her gender affected her experience in the classroom. One reason is because she believes that women are more likely to admit when they have difficulty with physics. Specifically, she states that "the men in my class are a lot more likely to conceal the fact they're struggling than women". When men outnumber women in a learning environment (as in calculus-based courses like Samantha took), struggling with physics concepts becomes an isolating experience. Samantha shares, "it makes me feel like I'm one of the few that's struggling with things, with certain problems." According to Samantha, men did not openly share their struggles; we suggest that this may be attributed to men's pride and the masculine culture of physics.

According to Samantha, another behavior that isolates women is men's high sense of confidence in speaking about physics topics. She shares that men in her cohort "either have the same level of knowledge on something, or maybe I'm even a little more knowledgeable than them, and they will be really confident about speaking about something that they don't have complete knowledge about, whereas I feel like I need to have a really good level of knowledge before I can like talk about something." She believes that her male peers' high confidence can influence an alienating environment which can also perpetuate stereotypes that men understand physics better than women do. This is concerning because students in the class may interpret men's confidence as a sign that stereotypes about who belongs in physics are true, even though this confidence is not based on performance.

Women also had negative experiences with male peers in research groups. Evelyn shares how her gender affected her research experience. She describes a male peer as condescending and not someone she would have chosen to work with because he would ignore her inputs and "mansplain" (mansplaining is a term that describes men explaining something to a woman in a condescending or overconfident way [37-39]) concepts to her. She says, "I would say something and he'd ignore it and I would end up being right and he wouldn't acknowledge that, like, he ignored me, or I would say something and he would go, 'No, no, no, no,' and then he would... explain it to me, like the same thing that I said, like in different words." It is clear that in Evelyn's experience, her male peers did not like receiving input from their female peers even if they were correct. She also recalls a similar experience while working on homework sets with her male peers, during which she suggested different ideas, "if I said I got different answers, [they were] always like, 'No, you're wrong.' And a lot of times I wasn't wrong, I was right, so it was like, frustrating to have someone constantly, like project that onto me like, 'you're wrong, you're wrong, you're wrong.'... even when I was right, I never felt as good as I should because it felt like there was still someone who was just like, first instinct was to think that I was wrong." From Evelyn's experiences, we see that male peers have implicit biases against women and 
their academic contributions. Whether or not male students are aware of their biases and behaviors towards women, the remaining effect is harmful and makes women feel uncomfortable to occupy the same spaces in physics.

\section{B. Uncomfortable environments created by male instructors}

The students we interviewed were not only affected negatively by peers, but instructors as well. This is particularly concerning, because instructors have the ability to influence the learning environment of many students. Unfortunately, instructors can negatively impact the physics culture by perpetuating stereotypes about underrepresented students such as women in physics and astronomy. In this section we share Mary's, Samantha's, and Evelyn's perspectives and experiences with male instructors and how they influenced an intimidating and isolating physics environment.

Mary recalls that after taking an exam for one of her introductory physics courses, she attended her instructor's office hours for clarification on a problem she struggled on. She says that her instructor tried to help her by prompting her with many of questions, in a similar style to the Socratic method, to help her learn how to approach problems she didn't know how to do. She explains, "he had been talking about,... 'you should answer questions until you don't know how and then you should look for ways to figure out how." According to Mary, another student attended his office hours and the instructor, "would ask him questions until he didn't know stuff and then he could go like, learn it. And so I was like, intimidated by this other kid in there doing that." Her experience shows that being subjected to a method similar to the Socratic method was intimidating especially when another student was present and able to answer questions. Mary may have felt pressured to go through the method, which could be overbearing for students, while another student was also being asked similar questions. Had the instructor provided more support during his office hours, Mary might not have felt intimidated.

In Samantha's experience, she noticed that before she began her undergraduate career, she never encountered instructors' disparaging language. She explains when she began her introductory physics courses during her first year, she noticed that her instructors used phrases such as "This is trivial, and you should know this, right?" We note that it is the impact of these phrases that matter, not the intention of the instructors. She also observes that after her instructors used phrases like these in her classes, her peers began using them as well. Furthermore, Samantha adds, "I feel like it's something that's almost like, also taught along with the curriculum is like, this is how physics culture is in those first, like, couple of physics classes you take in college." Her insight implies that instructors have a large influence in setting the tone and environment, i.e. physics culture, in classrooms and even perpetuate stereotypes that physics is easy. Samantha also emphasizes, "I felt like the... disrespectful behaviors that compose the culture and physics were taught in my first year at Pitt, through like, professors using this language in their lectures that other people started to pick up on from their use." Male students might see their instructors as role models to some extent. Therefore, when instructors use words or behaviors that are derogatory towards students who are at risk of being excluded, male students can adopt and propagate the same words and behaviors. Despite instructors having a responsibility to create a safe learning environment, their behaviors can be harmful towards women.

Evelyn had similar experiences to both Mary and Samantha in regards to instructors' language affecting how they feel in the classroom. For example, instructors using condescending language which implies that physics is easy, in addition to classes being mainly composed of men, affects womens' confidence. Evelyn explains, "if you don't think [that physics is easy], you immediately are like, 'Oh, there's something wrong with me... I'm missing this super obvious thing.' So that's frustrating." Her experience gives insight about how instructors can make students feel guilty and the direct result is in shifting the blame onto students for not understanding physics concepts when it is the responsibility of the instructor to create an equitable learning environment. Evelyn gives an example in which her instructors belittled her when she attended their office hours, "I've had teachers like mock me almost, or like, scoff when I asked a question." This behavior is alarming and may affect how a student views themself in regards to being able to do physics and belonging in physics. Evelyn provides another example about attending an instructor's office hours. She says that whenever she asked questions, their response would be, "Well,... did you read the book?" Her response to this question was, "Yeah, I read the book, and I still don't understand this like concept." She explains, "it's like, they don't want to help you or... they feel like making you feel bad about not knowing it is going to... help push you to learn it, which in my experience is not true, because it just feels bad when your teacher thinks you're dumb." Again, Evelyn's experiences show that instructors can make students feel guilty about not understanding physics concepts by questioning their effort.

\section{Suggestions for improving women's experiences}

When asked about how the physics and astronomy department could be improved, the women provided several suggestions. Here we address the three they mentioned the most.

Mentoring and increasing visibility: Mary suggests that it would be beneficial to get to know more women in the department. She explains that this could be done as part of the mentoring program that the SPS chapter at her university could implement. She says, "if you like match the upperclassmen women to the younger underclassmen women, then like, first of all they would know that there's other women in the department and there's other women who are like being successful in being in the department." By matching more experienced undergraduate women to younger undergraduate women, younger women in physics and astronomy, such as Mary, will benefit by meeting other women in their cohort and the department who can provide advice and guidancetopics may include tutoring, careers, research, etc.-or form 
a community in which women feel safe. These women will also be introduced to other women such as graduate students and women faculty who can serve as role models and help them navigate physics, and thus help them develop a stronger physics identity.

In addition to one-on-one mentoring, Samantha mentions a social support her department had already begun to implement: a club for women in physics and astronomy. Specifically, she views involving men may educate them on what women in the department experience. Samantha explains, "I'm hoping that more men... become aware about it, because I think addressing it is very... polarizing like, 'we are women and we're fighting this problem,' is going to make a lot of people defensive and so I think the fact that we are also inviting men is really good, because I think that it is going to help solve the problem more." Clubs and programs such as these may inspire change within the physics culture by educating students about women's struggles.

Accountability for students and instructors: When asked about what the department can do to support women in physics and astronomy, Samantha suggests that instructors should be responsible for establishing and maintaining a positive learning environment. She says, "I want [instructors] to be obligated, when they witness [microaggressions] happen in their classes with other students, to confront them, the students who [perform microaggressions] because the problem just isn't with professors, it's with professors and studentsstudents feel like they can do that-these things after they see their professors do it." She suggests that instructors be held accountable for their actions as well as report microaggressions that may occur within their classrooms. We believe that Samantha hints at establishing regulations (e.g. a code of conduct) that would outline how to address microaggressions in the classrooms.

Feedback for instructors: In addition to having regulations about how to hold department members accountable, Evelyn suggests a method for communicating with instructors about their behaviors. She adds that "there have been times where professors have like, said things that I did not think were appropriate and... I've never really said anything, because I was like, 'Well, what's it gonna matter?' But now I try and use the OMETS... [to] be genuine with my feedback and be like, 'this is how I felt in your class and like, this is how I felt other people might have felt." OMETS, short for Office of Measurement and Evaluation of Teaching, are teaching surveys used to gain student feedback about teaching effectiveness. Being able to provide instructors feedback about their course and behaviors may be beneficial by informing instructors about their harmful behaviors towards women and other minoritized students. This could be a way for students to directly give instructors feedback without putting students at jeopardy.

Training for students and instructors: Samantha adds that members of the physics department could be required to attend training sessions in order to identify microaggressions. She says, "I think everyone needs [microaggressions] explicitly explained to them, because it's really complicated and people don't get it, whether they're the people... who like are the cause of the [microagressions] or the people who are the victims of this stuff... people need to learn how to identify it better from the start of their physics career." Both instructors and students should have access to resources and thus be able to identify microaggressions. By educating members of the physics department about microaggressions, it may become easier for students to report or even stand up for their peers (i.e., bystander training). Samantha reveals that "if people were talking that way to me... I kind of confused it with me not being knowledgeable enough about something or like... it was my fault." Properly educating students about harmful behaviors would reduce ambiguities and can lessen discrimination against women.

\section{CONCLUSIONS}

By analyzing empathetic, semi-structured interviews with standpoint theory as our framework, we focus on underrepresented students, such as women in physics, and their experiences in an undergraduate physics and astronomy program. Empathetic interviews reveal how these students navigate the physics major and the barriers they face. For these three women, we note that both male students and instructors create a physics culture that is dominated by traditional beliefs about who can do physics and who belongs in physics. As a result of condescending attitudes, which are enabled by instructors and carried through by students, undergraduate women in physics feel isolated and uncomfortable.

Despite being subjected to an unwelcoming physics culture and environment, the undergraduate women provided suggestions on how to combat their male peers' and male instructors' behaviors. Their suggestions include the formation of programs and clubs that bring together women to mentor younger women, and educate both men and women to work towards reducing bias and discrimination. Another suggestion is to hold physicists accountable in the classroom as well as creating a method in which students can provide feedback for instructors to inform them about how their actions affect students and what they can do to improve. The final suggestion discussed here is to provide access to training sessions that would educate members of the department in order to help male students and peers realize the negative impact their actions have on women. Educating women within the department would also benefit them, e.g., by providing examples of discrimination that they may potentially experience or witness during their undergraduate career.

Regardless of whether or not men intentionally alienate women through their actions, they play a critical role in bringing about change within the physics culture. Based on women's experiences, we see that men have significant influence in setting the tone both inside and outside of the classroom. Therefore, one can argue that men potentially have the means by which to improve the physics culture by combating their harmful actions and learning how to be allies to women.

\section{ACKNOWLEDGEMENTS}

We thank NSF for award PHY-1806691. 
[1] P. J. Mulvey and S. Nicholson, Physics bachelor's degrees: 2018, retreived from: https://www.aip.org/statistics/reports/ physics-bachelors-degrees-2018 (2020).

[2] A. Porter and R. Ivie, Women in physics and astronomy, 2019, retrieved from: https://www.aip.org/statistics/reports/ women-physics-and-astronomy-2019 (2019).

[3] E. Seymour and N. M. Hewitt, Talking About Leaving: Why Undergraduates Leave the Sciences (Westview Press, Boulder, CO, 1997).

[4] E. Seymour and A.-B. Hunter, Talking About Leaving Revisited: Persistence, Relocation, and Loss in Undergraduate STEM Education (Springer, 2019).

[5] E. Pollack, The Only Woman in the Room: Why Science Is Still a Boys' Club (The Beacon Press, 2016).

[6] S. J. Correll, Gender and the career choice process: The role of biased self-assessments, Am. J. Sociol. 106, 1691 (2001).

[7] R. M. Felder, G. N. Felder, M. Mauney, C. E. Hamrin Jr., and E. J. Dietz, A longitudinal study of engineering student performance and retention. iii. gender differences in student performance and attitudes, J. Eng. Educ. 84, 151 (1995).

[8] S.-J. Leslie, A. Cimpian, M. Meyer, and E. Freeland, Expectations of brilliance underlie gender distributions across academic disciplines, Science 347, 262 (2015).

[9] Z. Hazari, G. Sonnert, P. M. Sadler, and M.-C. Shanahan, Connecting high school physics experiences, outcome expectations, physics identity, and physics career choice: A gender study, J. Res. Sci. Teach. 47, 978 (2010).

[10] Z. Y. Kalender, E. Marshman, C. D. Schunn, T. J. NokesMalach, and C. Singh, Damage caused by women's lower selfefficacy on physics learning, Phys. Rev. Phys. Educ. Res. 16, 010118 (2020).

[11] Z. Y. Kalender, E. Marshman, C. D. Schunn, T. J. NokesMalach, and C. Singh, Why female science, technology, engineering, and mathematics majors do not identify with physics: They do not think others see them that way, Phys. Rev. Phys. Educ. Res. 15, 020148 (2019).

[12] J. M. Nissen and J. T. Shemwell, Gender, experience, and selfefficacy in introductory physics, Phys. Rev. Phys. Educ. Res. 12, 020105 (2016).

[13] A. L. Zeldin, S. L. Britner, and F. Pajares, A comparative study of the self-efficacy beliefs of successful men and women in mathematics, science, and technology careers, J. Res. Sci. Teach. 45, 1036 (2008).

[14] V. Sawtelle, E. Brewe, and L. H. Kramer, Exploring the relationship between self-efficacy and retention in introductory physics, J. Res. Sci. Teach. 49, 1096 (2012).

[15] Y. Li, K. Whitcomb, and C. Singh, How perception of being recognized or not recognized by instructors as a "physics person" impacts male and female students' self-efficacy and performance, Phys. Teach. 58, 484 (2020).

[16] Z. Y. Kalender, E. Marshman, C. D. Schunn, T. J. NokesMalach, and C. Singh, Gendered patterns in the construction of physics identity from motivational factors, Phys. Rev. Phys. Educ. Res. 15, 020119 (2019).

[17] A. Bandura, Self-Efficacy: The Exercise of Control (W. H. Freeman, New York, 1997).

[18] R. Masika and J. Jones, Building student belonging and engagement: Insights into higher education students' experiences of participating and learning together, Teach. High. Educ. 21,
138 (2016).

[19] C. Goodenow, Classroom belonging among early adolescent students: Relationships to motivation and achievement, J. Early Adolescence 13, 21 (1993).

[20] K. M. Whitcomb, Z. Y. Kalender, T. J. Nokes-Malach, C. D. Schunn, and C. Singh, Comparison of self-efficacy and performance of engineering undergraduate women and men, Int. J. Eng. Educ. 36, 1194 (2020).

[21] E. Marshman, Z. Y. Kalender, C. Schunn, and C. Singh, Female students with A's have similar physics self-efficacy as male students with C's in introductory courses: A cause for alarm?, Phys. Rev. Phys. Educ. 96, 391 (2018).

[22] E. Marshman, Z. Y. Kalender, C. Schunn, T. Nokes-Malach, and C. Singh, A longitudinal analysis of students' motivational characteristics in introductory physics courses: Gender differences, Can. J. Phys. 96, 391 (2018).

[23] M. Allen, Women discouraged by masculine culture in physics, Phys. World 29, 11 (2016).

[24] A. Maries, N. I. Karim, and C. Singh, Is agreeing with a gender stereotype correlated with the performance of female students in introductory physics?, Phys. Rev. Phys. Educ. 14, 020119 (2018).

[25] A. Maries, N. I. Karim, and C. Singh, Active learning in an inequitable learning environment can increase the gender performance gap: The negative impact of stereotype threat, Phys. Teach. 58, 430 (2020).

[26] N. I. Karim, A. Maries, and C. Singh, Do evidence-based active-engagement courses reduce the gender gap in introductory physics?, Eur. J. Phys. 39, 025701 (2018).

[27] B. Francis, L. Archer, J. Moote, J. DeWitt, E. MacLeod, and L. Yeomans, The construction of physics as a quintessentially masculine subject: Young people's perceptions of gender issues in access to physics, Sex Roles 76, 156 (2017).

[28] A. T. Danielsson, Exploring woman university physics students 'doing gender' and 'doing physics', Gender Edu. 24, 25 (2012).

[29] R. S. Barthelemy, M. McCormick, and C. Henderson, Gender discrimination in physics and astronomy: Graduate student experiences of sexism and gender microaggressions, Phys. Rev. Phys. Educ. Res. 12, 020119 (2016).

[30] D. Doucette and C. Singh, Why are there so few women in physics? reflections on the experiences of two women, Phys. Teach. 58, 297 (2020).

[31] S. G. Harding, The Feminist Standpoint Theory Reader: Intellectual and Political Controversies (Routledge, New York, 2004).

[32] K. Rolin, Standpoint theory as a methodology for the study of power relations, Hypatia 24, 218 (2009).

[33] H. E. Longino, Feminist standpoint theory and the problems of knowledge, Signs 19, 201 (1993).

[34] S. Kvale and S. Brinkmann, Interviews: Learning the Craft of Qualitative Research Interviewing, 3rd ed. (SAGE, 2014).

[35] J. Fereday and E. Muir-Cochrane, Demonstrating rigor using thematic analysis: A hybrid approach of inductive and deductive coding and theme development, Int. J. Qual. Meth. 5, 80 (2006).

[36] J. Saldaña, The Coding Manual for Qualitative Researchers, 2nd ed. (SAGE, 2013).

[37] Merriam-Webster Dictionary, Mansplain, https://www. merriam-webster.com/dictionary/mansplaining (2021). 
[38] J. Bridges, Gendering metapragmatics in online discourse: "mansplaining man gonna mansplain...", Discourse, Context \& Media 20, 94 (2017).
[39] R. Solnit, Men Explain Things to Me (Haymarket Books, Chicago, Illinois, 2014). 